Products and Services In Practice is provided to readers using text and images from the manufacturer, supplier or distributor and does not imply endorsement by BDJ In Practice. Normal and prudent research should be exercised before purchase or use of any product mentioned.

Please send product and services news through to David Westgarth, BDJ In Practice via: David.Westgarth@bda.org

\section{Lending a hand}

Are you worried about being unable to perform a complex endodontic case? Perhaps you have patients who suffer from extreme anxieties or dental phobia which makes them difficult to treat?

Keep things simple and let EndoCare lend a hand! The whole team at EndoCare are highly trained endodontic specialists and are completely up to date with all of the latest treatment options and methods in the field.

Furthermore, EndoCare practices are the perfect option for nervous patients. We offer the opportunity to listen to music or watch movies before and during treatment, and due to our commitment to pain-free dentistry we ensure that all of our procedures are as comfortable as possible.

Find out more about referring to EndoCare today by contacting the team on 02072240999 or visit www.endocare.co.uk

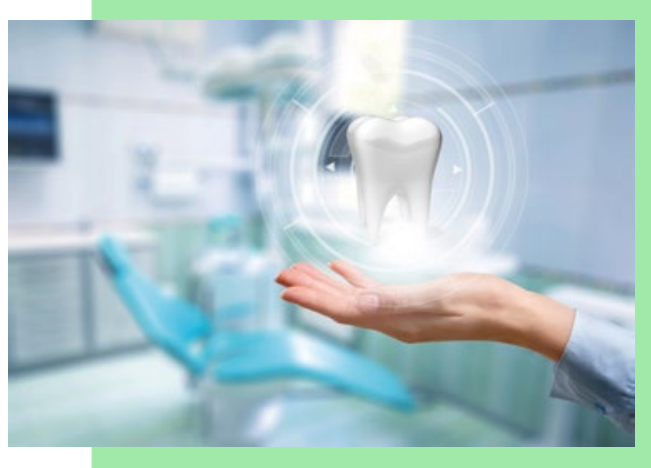

\title{
Mentoring - top of the list
}

When learning a new skill or developing existing capabilities, the support and guidance of a mentor is invaluable.

That's why IAS Academy offers access to in-depth support through its online hub. The mentoring panel consists of an array of leading clinicians in the field, including IAS

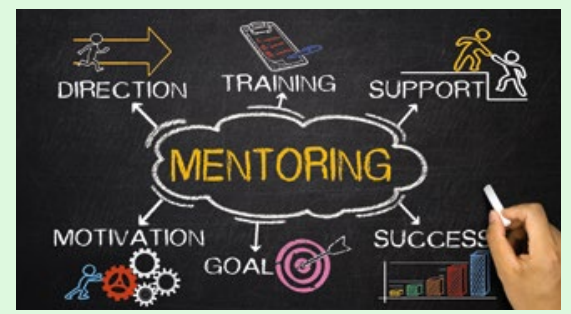

Academy Directors Tif Qureshi and Ross Hobson, as well as specialist orthodontist Asif Chatoo and many others. They provide bespoke, case-specific advice on everything from diagnosis to treatment planning and execution, ensuring colleagues can deliver safe, ethical and effective patient care.

The open source mentoring programme is available to GDPs using any orthodontic system for an affordable monthly fee, with discounts available to IAS appliance users.

For more information on this and the many other IAS Academy membership benefits available, visit www.iasortho.com or call 01932336470 (press 1).

\section{Hand care that makes a difference}

Hand hygiene is incredibly important to follow in order to prevent the spread of disease in your dental practice.

So why not ensure pathogens have no chance of transferring to other surfaces by choosing the Steri-7 Xtra range of disinfectants from Initial Medical?

The Personal Care Range includes a hypoallergenic surgical level hand rub and wash. These products can be used in the surgery but also in washrooms and other spaces where germs may be spread. They kill 99.9999\% of pathogens and also have Reactive Barrier Technology - an innovative feature that prevents pathogens recolonising treated surfaces for up to 72 hours.

For further information visit www.initial. co.uk/medical or call 0870850 4045.

\section{Cost-effective handpiece maintenance}

Handpiece maintenance is quick, easy and cost-effective with the new Assistina TWIN from W\&H. This is the first reprocessing device featuring two chambers that can be used alternately for non-stop loading.

The Assistina TWIN nebulises the oil into a dispersible mist that is discharged through the instrument at high pressure, thereby removing contamination from inside the instrument. Oiling of all gearing components and cleaning spray channels can be completed in just 10 seconds per handpiece, making rotational lubrication a thing of the past.

Cost-effective reprocessing of your instruments is further assured with the Assistina TWIN Care Set, which facilitates the maintenance of approximately 2,800 handpieces.

To find out more visit www.wh.com/en_uk, call 01727874990 or email office.uk@wh.com.

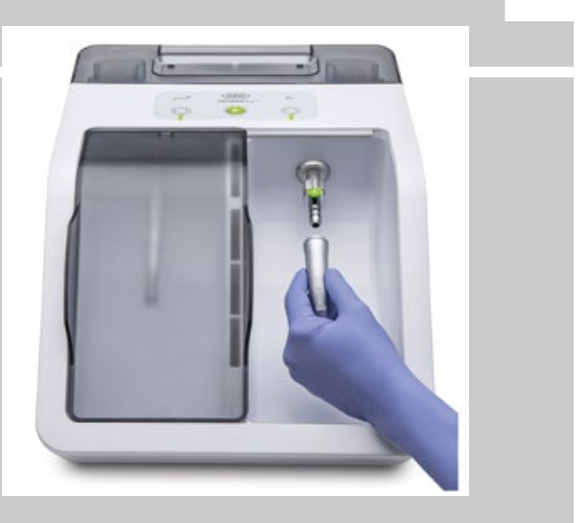

